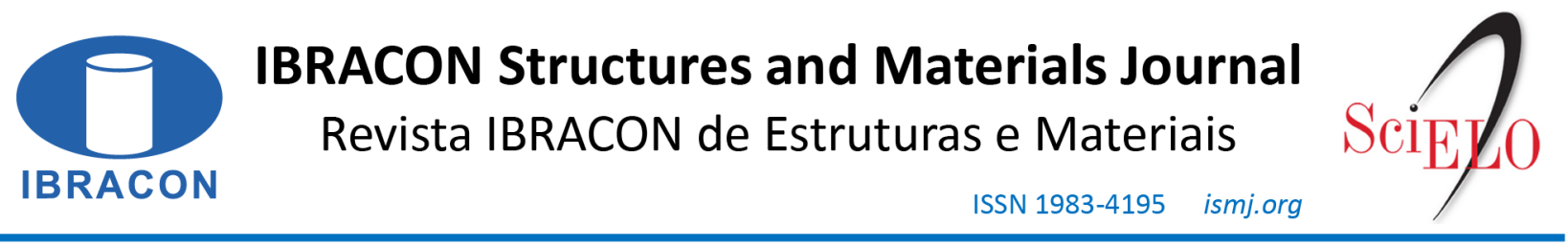

ORIGINAL ARTICLE

\title{
Reliability analysis of truss structures considering complete failure paths and using the FLHB model
}

\section{Análise de confiabilidade de treliças considerando caminhos de falha e utilizando o modelo FLHB}

Túlio Raunyr Cândido Felipe ${ }^{\mathrm{a}}$ (D)

Edson Denner Leonel ${ }^{\mathrm{b}}$ (1)

Vladimir Guilherme Haach ${ }^{\mathrm{b}}$

André Teófilo Beck ${ }^{\mathrm{b}}$

${ }^{a}$ Marinha do Brasil, Diretoria de Obras Civis da Marinha, Rio de Janeiro, RJ, Brasil

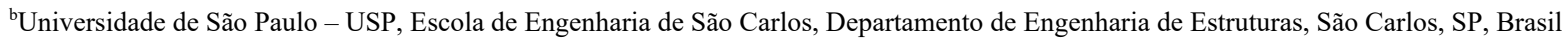

Received 10 August 2020

Accepted 05 December 2020

\begin{abstract}
The study of progressive collapse of structures using numerical models requires accurate modeling of geometrical nonlinearity and material failure behavior. Numerical models must demonstrate stability, such that localized member failures do not trigger numerical instabilities. Also, algorithms should be efficient, to limit the computational burden of analyzing multiple responses when considering the effects of uncertain loads, geometric and material variables. In this scientific domain, a comprehensive non-linear ductile-damage truss-element model has been recently presented by the authors. The model accounts for the geometrical and material nonlinearities observed during progressive collapse of structural systems. In this paper, the FelipeLeonel-Haach-Beck (FLHB) model is calibrated to describe the response of Ultra-High-Performance Fiber Reinforced Concrete (UHPFRC). Based on a limited number of UHPFRC experimental curves, statistics of FLHB model parameters are obtained. These are employed in the probabilistic analysis of failure paths of truss structures under progressive collapse. Monte Carlo Simulation and the First Order Reliability Method are employed in the probabilistic failure path analyses. Six application examples demonstrate the accuracy, robustness, and efficiency of the FLHB model in evaluation of failure paths of realistic structural systems.
\end{abstract}

Keywords: progressive collapse, failure paths, truss structures, continuum damage mechanics, reliability analysis.

\begin{abstract}
Resumo: O estudo do colapso progressivo de estruturas, utilizando análise numérica, requer modelos precisos das não-linearidades geométrica e material. Modelos numéricos também precisam se mostrar estáveis, de forma que a falha localizada de um elemento não provoque instabilidades numéricas. Algoritmos precisam ser eficientes, de forma a possibilitar as análises repetitivas, necessárias para avaliar os efeitos das incertezas nas ações, na geometria e nos parâmetros de resistência dos materiais. Neste contexto, um modelo não-linear abrangente foi apresentado recentemente pelos autores, combinando análise plástica com um modelo de dano, para análise de treliças. O modelo leva em conta as não-linearidades material e geométrica observadas durante o colapso progressivo de estruturas hiperestáticas. Neste artigo, o modelo de Felipe-Leonel-Haach-Beck (FLHB) é calibrado para descrever a resposta do concreto de ultra-alto desempenho reforçado com fibras ou Ultra-HighPerformance Fiber Reinforced Concrete (UHPFRC). Com base em um número limitado de curvas experimentais para o UHPFRC, estatísticas dos parâmetros do modelo FLHB são obtidas. Estas são utilizadas em uma análise probabilística dos caminhos de falha de treliças sob colapso progressivo. Simulação de Monte Carlo e o Método de Confiabilidade de Primeira Ordem são empregados nas análises. A aplicação a seis estruturas-exemplo demonstram a precisão, robustez e eficiência do modelo FLHB em avaliar os caminhos de falha de treliças realísticas.
\end{abstract}

Palavras-chave: colapso progressivo, caminhos de falha, treliças, mecânica do dano continuo; confiabilidade estrutural. 
How to cite: T. R. C. Felipe, E. D. Leonel, V. G. Haach, and A. T. Beck, "Reliability analysis of truss structures considering complete failure paths and using the FLHB model" Rev. IBRACON Estrut. Mater., vol. 14, no. 4, e14402, 2021, https://doi.org/10.1590/S1983-41952021000400002

\section{INTRODUCTION}

Partial collapses such as Ronan Point Tower and Skyline Plaza, and terrorist attacks like those at Oklahoma City and World Trade Center have raised awareness about the importance of robust design, with objective consideration of progressive collapse following local damage by abnormal loads. The new paradigm of robust design requires that structural systems withstand localized damage due to the abnormal loads, without disproportionate extension of the initial damage to the rest of the structural system. Abnormal loads include gas explosions, fire, vehicular collisions, human errors, deterioration processes, and terrorist attacks. Because these loads are characterized by very low probabilities of occurrence and very large impact, structural elements are not always designed to withstand them. Instead, the structural system is designed to withstand the loss of individual elements, which may occur due to such actions. In other words, structural systems should be made robust concerning the loss of individual elements due to abnormal loading.

As well documented in the literature review by Adam et al. [1], numerical modeling is often employed in progressive collapse analysis, as a cheaper complement or substitute for experimental testing. Numerical analysis for progressive collapse can be made using the Finite Element Method (FEM), the Discrete Element Method (DEM), the Applied Element Method (AEM) or Cohesive Element Modeling (CEM). An overview of these methods and discussions about the advantages and disadvantages are presented in Adam et al. [1]. The following elements have been required for proper analysis of progressive collapse using numerical models:

a) non-linear geometrical analysis: due to the large displacements triggered by element failures;

b) non-linear material modeling: to represent material failure, including plasticity and damage;

c) non-linear contact mechanics: to allow for debris pile-up;

d) dynamic analysis: because load re-distributions occur dynamically, or with dynamic load amplification;

e) stability of numerical algorithms: because localized element failures should not trigger numerical instability due to zero tangent stiffness;

f) efficiency: to allow (repetitive) non-linear analysis of real-world structures.

Different methods offer different trade-offs among the requirements above. The DEM and AEM methods are excellent at describing very large displacements and debris pile-up, but the computational cost of solutions is very high. AEM and CEM have the disadvantage that fracture zones need to be identified previously by the user when constructing the model. This paper presents a development in FEM, which is computationally efficient for truss collapse analysis, but which does not aim to compete with other special capabilities of DEM, AEM or CEM.

Complementing points a) to f) above, probabilistic or reliability analysis of progressive collapse is widely desired [2]-[8] because of the large uncertainties involved in material and element failures [9] and due to a large number of hazard loading events with low probability of occurrence. In probabilistic analyses, points e) and f) above increase in importance, as progressive analyses need to be repeated hundreds to thousands of times, considering different realizations of the problem's random variables.

Felipe et al. [10] have introduced a Finite Element (FE) model which is well suited for progressive collapse analysis of truss structures. The model combines the positional FE method, which can handle large displacements, with a ductiledamage model for material failure modeling. The material model considers continuum damage accumulation due to porosity variation. Material damage is related to the hydrostatic component of plastic strains. One unique feature of this model is that critical damage converges to the theoretical limit hypothesized by Lemaitre [11]; hence avoiding the tangent matrix to become ill-conditioned. Hence, individual elements fail, and loads are smoothly re-distributed to other undamaged or less-damaged members. The formulation has been used to describe the exact equilibrium path of different truss structures. Herein, the formulation in Felipe et al. [10] is referred to using the initials of the four authors: the Felipe-Leonel-Haach-Beck (FLHB) model.

This paper extends the results in Felipe et al. [10] in three ways: by calibrating FLHB model parameters to describe the behavior of Ultra-High-Performance Fiber Reinforced Concrete (UHPFRC); by performing a statistical analysis of FLHB model parameters for UHPFRC; and by employing the model in reliability analysis of failure paths of truss structures. The extended model can be utilized in the progressive collapse analysis of truss structures such as bridges and domes. 
Progressive collapse of truss structure domes has been studied recently by Yan et al. [12] and Tian et al. [13], using bi-linear elastic-plastic material models. As will be shown herein, consideration of material failure (damage) produces significant changes in the equilibrium path of truss structures.

An extensive literature review reveals few papers addressing progressive failure paths with a probabilistic perspective. Miao and Ghosn [14], [15] studied the reliability-based progressive collapse of highway bridges; the authors used simple analytical models and derived recommended minimal reliability indexes for intact and damaged structures. Ding et al. [16] addressed reliability of steel frames subject to blast loads; the post-blast stage is evaluated by non-linear 3D finite element analysis. A similar analysis of steel-concrete slabs was performed by the same authors in Ding et al. [17] and Feng et al. [18] studied reliability and robustness of reinforced concrete frames against progressive collapse, considering damage and plasticity. As observed, few papers in the literature address reliability analysis of progressive failure paths. The above references are from the last three years, showing that this is also a recent topic.

Due to highly non-linear material behavior at failure, probabilistic analysis of failure paths is usually done using Monte Carlo simulation, using subset simulation [14]-[16] or Latin Hypercube sampling [17]. One exception is Feng et al. [18], where the probability density evolution method is employed. Because the proposed FLHB numerical formulation is fast/efficient for truss structures, brute force Monte Carlo simulation is adopted herein. However, for limit states involving critical displacements in the equilibrium path, it is shown that the First Order Reliability Method (FORM) also provides very accurate results.

Three application examples demonstrate the accuracy, robustness, and performance of the proposed numerical scheme. Real structures have been analyzed and the performance of the proposed formulation contributes to the state of the art of this scientific domain.

\section{A TOTAL-LAGRANGIAN FORMULATION FOR MATERIAL AND GEOMETRICAL NONLINEAR ANALYSIS OF FAILURE PATHS}

Progressive collapse occurs when structures cannot totally dissipate the kinetic energy, after the occurrence of abnormal loads [19]-[22]. Among the complex energy dissipation mechanisms, there is the plastic work in element deformation and the energy dissipation associated with structural damping [23]. The response of structures during or at the brink of progressive collapse is highly nonlinear [24], [25]. Therefore, material and geometric nonlinearities need to be considered in the analysis of progressive collapse.

In this paper, the FLHB model in Felipe et al. [10] is employed in the reliability analysis of failure paths of concrete truss structures. The model is briefly summarized in this section. Theoretical and implementation details are given in Felipe et al. [10].

The model employs a log-strain measure $\left(\varepsilon_{l n}\right)$, which is decomposed in elastic and plastic terms. The model assumes: decoupling between elasticity-damage and plastic hardening [26]; von Mises yield criterion and isotropic hardening behavior; variation in porosity at the mesoscale equal to the hydrostatic component of the plastic strain (Gurson model [27]). Porosity variation is the result of growth and coalescence of microcavities. The total mechanical energy is written in terms of nodal positions (instead of displacements) [9], [28], [29].

In the softening regime, stress in the truss element is given by:

$\tau=(1-D) \aleph \varepsilon_{l n}^{e}=(1-D) \aleph\left(\varepsilon_{l n}-\varepsilon_{l n}^{p}\right)$

where $D$ is the damage variable, $M$ is the elastic modulus of the undamaged material, superscript $0^{e}$ refers to "elastic", and superscript $0^{p}$ refers to "plastic".

The damage evolution law is given in terms of three material parameters: $\alpha_{1}^{p}, \alpha_{2}^{p}$ and $\alpha_{3}^{p}[10]$.

$$
D(\varphi)=\alpha_{1}^{p}\left(\varphi-\varepsilon_{l n, d}^{p}\right)^{2}+\alpha_{2}^{p}\left(\varphi-\varepsilon_{l n, d}^{p}\right)+\alpha_{3}^{p}
$$

where $\varphi$ is the plastic extension measure and $\varepsilon_{l n, d}^{p}$ is the initial damage threshold (the fourth parameter to be determined). Thus, the stress-strain response of a structural material is described by two usual parameters: the elastic 
modulus $(\aleph)$ and the yield stress $\left(\tau_{y}\right)$, and four new parameters to be determined: $\alpha_{1}^{p}, \alpha_{2}^{p}, \alpha_{3}^{p}$ and $\varepsilon_{l n, d}^{p}$. In Felipe et al. [10], this model was shown to accurately represent complete stress-strain curves of mild iron, high strength low-alloy steel, copper, aluminum, ASTM A36 steel, gray cast iron, and conventional concrete. In this paper, the model is extended to cover Ultra-High-Performance Fiber Reinforced Concrete (UHPFRC).

One important feature of the FLHB model is that the damage variable in Equation 2 converges to the theoretical critical damage $\left(D_{\text {crit }}\right)$ hypothesized by Lemaitre [11], and given by:

$$
D_{c r i t}=1-\frac{\tau_{r}}{\tau_{u}}
$$

where $\tau_{r}$ is the rupture stress and $\tau_{u}$ is the ultimate stress. This is particularly relevant for progressive collapse analysis, as it avoids instability of the Hessian matrix, when an isolated truss element fails. Hence, computations can progress in a stable manner, with the load in the failed element being distributed to adjacent elements, until the complete structural collapse.

The solution scheme for the non-linear system of FE equations is based on the Newton-Raphson algorithm with displacement control.

\section{MODEL CALIBRATION FOR UHPFRC}

In Felipe et al. [10], the FLHB model just reviewed was employed in mechanical analysis of the fully nonlinear stress-strain response of mild iron, high strength low-alloy steel, copper, aluminum, ASTM A36 steel, gray cast iron, and conventional concrete. Herein, the FLHB model is employed in representing the nonlinear response of UHPFRC. UHPFRC is a modern building material and its application in complex engineering structures has increased in the last few years. One practical example is the Oveja Ravine truss footbridge constructed with UHPFRC in Alicante, Spain. Therefore, the analyses below are relevant to the state of the art of nonlinear problems.

The validations refer to uniaxial tests, in which cylindrical specimens have been subject to tensile/compression tests. The specimen dimensions are presented in Table 1. Six specimens are considered in compression, and six in tension (all with identical dimensions). Fiber content of UHPFRC is $2 \%$. Numerical simulations utilize a single finite element and four hundred load steps. The boundary conditions are as follows: uniform axial displacement imposed in one end; fixed (zero) axial displacements at the opposite end. The convergence tolerance of $10^{-6}$ has been assumed, based on the norm of position changes (see Felipe et al. [10]).

For each experimental curve (to be presented), FLHB model parameters were found by simple least squares. The interested reader can refer to Felipe et al. [10] for details. Results are summarized in Table 2: results for UHPFRC are the mean values (from six curves).

Table 1. Material and geometric data of specimens.

\begin{tabular}{|c|c|c|c|c|c|}
\hline Specimen & Figure & Material & Test & $l_{0}(\mathrm{~mm})$ & $A_{0}\left(\mathrm{~mm}^{2}\right)$ \\
\hline UHPFRC & 1 & \multirow{2}{*}{ brittle } & tensile & 80.0 & 900.0 \\
\hline UHPFRC & 2 & & compression & 100.0 & 1962.5 \\
\hline
\end{tabular}

Table 2. Material data for the mean FLHB model of UHPFRC.

\begin{tabular}{cccccccc}
\hline Specimen & $\boldsymbol{N}(\mathbf{M P a})$ & $\boldsymbol{\tau}_{\mathbf{y}}(\mathbf{M P a})$ & $\varepsilon_{l n, d}^{p}$ & $\alpha_{1}^{p}$ & $\alpha_{2}^{p}$ & $\alpha_{3}^{p}$ & $D_{\text {crit }}$ \\
\hline $\begin{array}{c}\text { UHPFRC in } \\
\text { tension }\end{array}$ & 43854 & 6.47 & $4.34 \cdot 10^{-4}$ & -2730.50 & 102.86 & 0.0 & 0.938 \\
\hline $\begin{array}{c}\text { UHPFRC in } \\
\text { compression }\end{array}$ & 43854 & 140.72 & $1.86 \cdot 10^{-4}$ & -46130 & 349.24 & 0.0 & 0.660 \\
\hline
\end{tabular}

Figures 1 and 2 show the stress-strain curves and tangent modulus for six UHPFRC specimens with 2\% of fibers in tensile and compression tests, respectively. The test results are taken from [30] In comparison to unreinforced concretes, the introduction of fibers reduces the growth of microcavities and the crack coalescence. Thus, it improves material 
ductility. As a result, UHPFRC presents peak strength higher than cracking strength. Then, when the material reaches the stress $\tau_{\mathrm{y}}$, it starts yielding with constant stress, until the initial damage threshold $\left(\varepsilon_{l n, d}^{p}\right)$. From this strain level, softening behavior governs the mechanical behavior of UHPFRC. In order not to overdraw Figures 1 and 2 with too many curves, results for the proposed model are shown only for the mean values of model parameters (Table 2). The proposed FLHB model leads to very good fit for each experimental curve, and also describes mean behavior, as shown. The accurate fit applies to stress-strain responses (Figures 1a and 2a), to predicted damage (Figures 1b and 2b), and to tangent modulus (Figures $1 \mathrm{c}$ and $2 \mathrm{c}$ ).

Figures $1 \mathrm{~b}$ and $2 \mathrm{~b}$ compare damage evolution in UHPFRC during tensile and compression tests. For the monotonic tests of UHPFRC, critical damage values (Equation 3) are as follows:

$$
D_{\text {crit }}^{\text {tensile }}=1-\frac{0.264}{8.336}=0.968 \text { and } D_{\text {crit }}^{\text {compression }}=1-\frac{37.98}{148.2}=0.744
$$
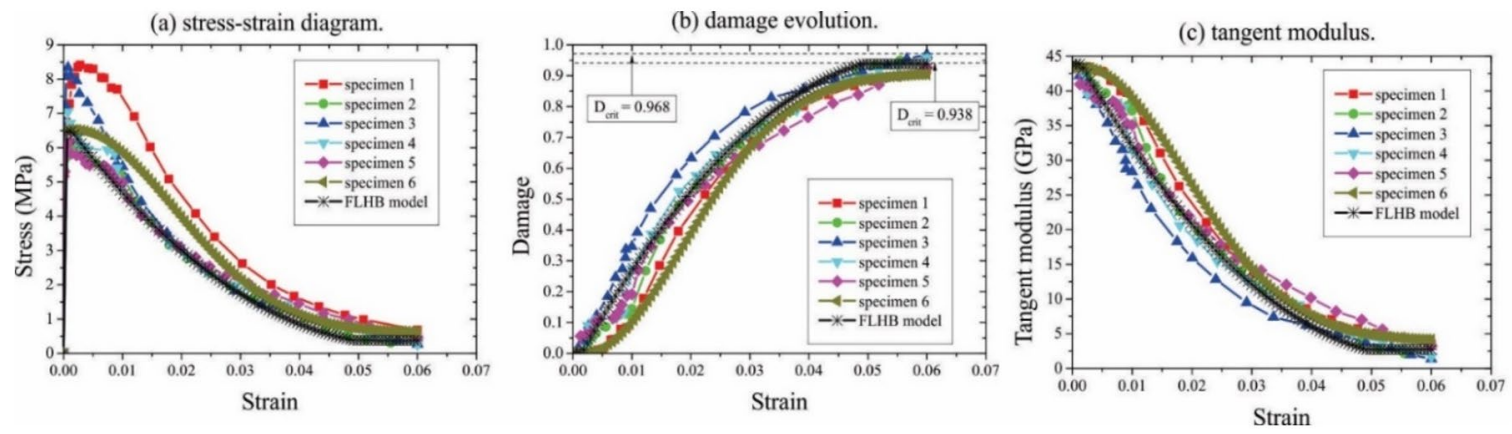

Figure 1. Tensile test at room temperature of UHPFRC with $2 \%$ of fibers [30]: (a) stress-strain diagram; (b) damage evolution and (c) tangent modulus.
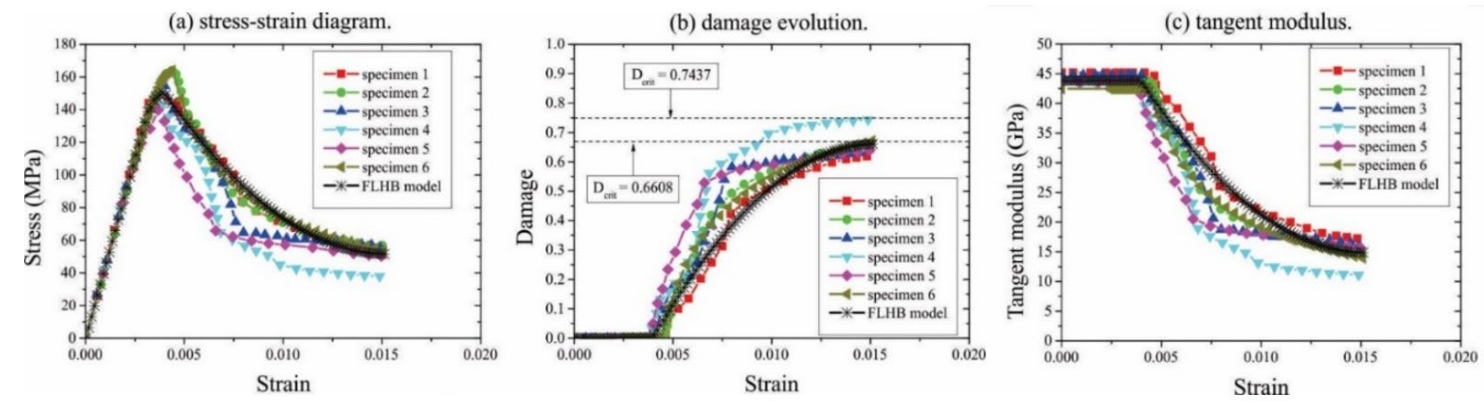

Figure 2. Axial compression at room temperature of UHPFRC with $2 \%$ of fibers [30]: (a) stress-strain diagram; (b) damage evolution and (c) tangent modulus.

As observed in Figures $1 \mathrm{~b}$ and $2 \mathrm{~b}$, the proposed model represents properly the damage evolution for UHPFRC. Note that damage evolution in the FLHB model converged to values slightly smaller than the critical damage. This leads to a tangent modulus value approximately equal to the value obtained in experimental curves. Consequently, the FLHB model does not experience instability in the Hessian matrix during computations. This behavior has major importance in the context of progressive collapse analysis because it enables the accurate failure modeling of an isolated truss member, without affecting the positive definiteness properties of the Hessian matrix.

Tables 3 and 4 present the results of a statistical analysis of the FLHB model parameters for UHPFRC, which is based on the twelve experimental responses illustrated in Figures 1 and 2. In this analysis, the model parameters are determined from a simple least square fit to each of the twelve experimental curves in Figures 1 and 2 . This gives one value of each model parameter for each experimental curve. Then, the EasyFit ${ }^{\circledR}$ software is employed to find a statistical distribution which describes the six data points, as well as the respective mean and standard deviation. Tables 3 and 4 
show the resulting distributions, which passed the chi-square and KS goodness-of-fit tests with $95 \%$ confidence. The large coefficient of variation (COV) of the initial damage threshold $\left(\varepsilon_{l n, d}^{p}\right)$ draws our attention, which is a consequence of the inherent material variability. We acknowledge that the available database was quite limited (only six samples); hence, the values in Tables 3 and 4 should not be taken as definite. This data is employed in Section 6 in the reliability analysis of the progressive collapse of a 3D truss structure.

Table 3. Statistics for FLHB model: UHPFRC in tension.

\begin{tabular}{cccc}
\hline Variable & mean & cov & Distribution \\
\hline \multirow{N}{*}{$(\mathbf{M P a})$} & 43854 & 0.023 & Uniform \\
\hline$\tau_{y}(\mathbf{M P a})$ & 6.47 & 0.115 & Normal \\
\hline$\varepsilon_{l n, d}^{p}$ & $4.34 \cdot 10^{-4}$ & 0.551 & Lognormal \\
\hline$\alpha_{1}^{p}$ & -2730.50 & -0.153 & Normal \\
\hline$\alpha_{2}^{p}$ & 102.86 & 0.088 & Gumbel Min \\
\hline$D_{c r i t}$ & 0.938 & 0.027 & Uniform
\end{tabular}

Table 4. Statistics for FLHB model: UHPFRC in compression.

\begin{tabular}{cccc}
\hline Variable & mean & cov & distribution \\
\hline$\kappa^{\prime}(\mathbf{M P a})$ & 43854 & 0.023 & Uniform \\
\hline$\tau_{y}(\mathbf{M P a})$ & 140.72 & 0.078 & Normal \\
\hline$\varepsilon_{l n, d}^{p}$ & $1.86 \cdot 10^{-4}$ & 0.417 & Lognormal \\
\hline$\alpha_{1}^{p}$ & -46130.0 & -0.206 & Gumbel Min \\
\hline$\alpha_{2}^{p}$ & 349.24 & 0.140 & Gumbel Min \\
\hline$D_{c r i t}$ & 0.660 & 0.064 &
\end{tabular}

\section{3D TRUSS FROM THE LITERATURE: COMPARISON OF CONVENTIONAL CONCRETE VERSUS UHPFRC}

The twelve-member 3D truss structure illustrated in Figure 3 is a reference example in several papers dealing with nonlinear analysis, e.g [31]-[33]. The proposed formulation is employed in the progressive collapse analysis of this 3D truss structure. The main purpose of this analysis is to compare the behavior of conventional and UHPFRC concrete. The example demonstrates the performance of UHPFRC in arresting progressive collapse, in comparison with conventional concrete.

This truss is composed of 9 nodes and 12 elements. The input data for UHPFRC elements is given in Table 2 . The cross-section area for conventional concrete elements is $A_{\text {concrete }}=4 A_{U H P F R C}=7850 \mathrm{~mm}^{2}$, which is four times larger than the cross-section area of UHPFRC elements (because the later has higher strength). Material parameters for conventional concrete are: $\kappa=32 \mathrm{GPa} ; \tau_{y}=12.7 \mathrm{MPa} ; \alpha_{1}^{p}=14696 ; \alpha_{2}^{p}=295.19 ; \alpha_{3}^{p}=-0.0216 ; \varepsilon_{l n, d}^{p}=3.72 \times 10^{-4}$ and $D_{\text {crit }}=0.441$, according to Felipe et al. [10]. Results are first obtained for geometrical non-linearity only, then for plasticity and damage.

Figure 4 presents the geometric non-linear responses obtained with the proposed formulation and by ANSYS ${ }^{\circledR}$ software. Constitutive law in ANSYS was modelled using the linear elastic model. Notice the good agreement among the responses. It is worth mentioning the accurate representation of the snap-through phenomenon for the displacement value of $49.5 \mathrm{~cm}$, which corresponds to forces of $28480 \mathrm{kN}$ and $83140 \mathrm{kN}$ for UHPFRC and conventional concrete, respectively. Moreover, for such 
force level, the Hessian matrix determinant is nil, which leads to neutral equilibrium. Consequently, the forces $28480 \mathrm{kN}$ (UHPFRC) and $83140 \mathrm{kN}$ (conventional concrete) represent the limit force values for this truss structure in a stable regime of static equilibrium, accounting for linear elastic material behavior. Notice that conventional concrete has higher stiffness than UHPFRC along the equilibrium trajectory, because $A_{\text {concrete }}=4 A_{\text {UHPFRC }}$. Then, the cross-section area value of the elements contributes directly to the Hessian matrix. For displacements in the range $49.5 \mathrm{~cm}$ to $240 \mathrm{~cm}$, convergence criterion in force cannot be applied because the Hessian matrix determinant is negative (unstable regime). Therefore, the load-displacement curves shown in Figure 4 have been achieved through a convergence criterion based on positions. Remark that the snap-through phenomenon shown in Figure 4 only appears when linear elastic behavior is assumed. When material nonlinearity is considered, these materials fail before snap-through, as discussed below.

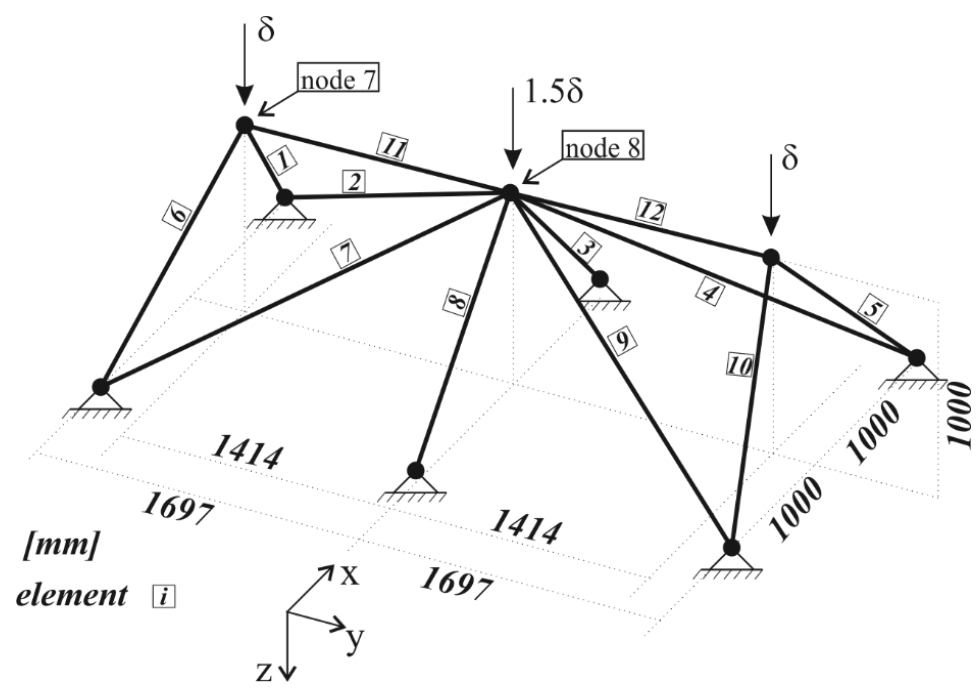

Figure 3. Geometric input data for twelve-member 3D truss.

Figure 5 shows the force vs. displacement curves for nodes 7 and 8 of the truss structure, accounting for geometric and material nonlinearities. It is worth noticing the different behaviors achieved when different modeling assumptions are made (linear elastic, plastic, and plastic with damage). Moreover, the responses presented in Figures 4 and 5 demonstrate clearly that the mechanical description based solely on geometric nonlinearities is not sufficient for the proper representation of the real mechanical structural behavior.

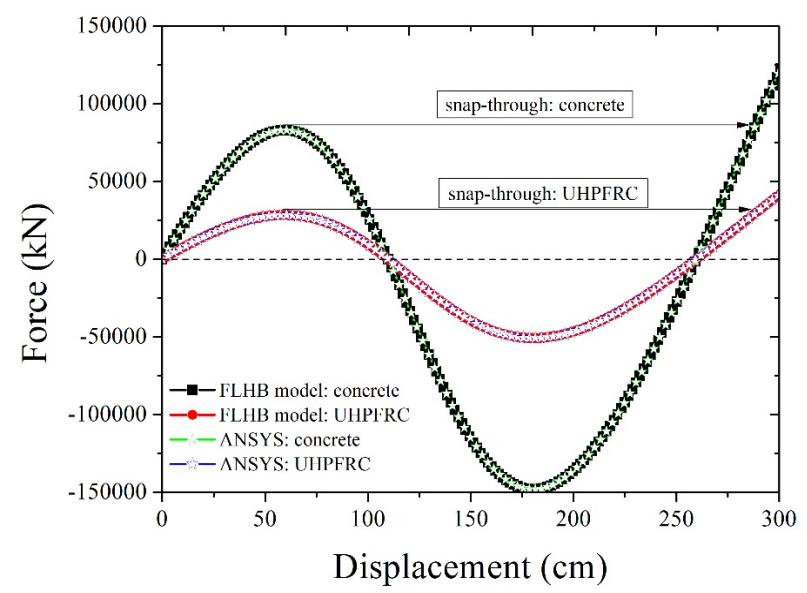

Figure 4. Vertical displacement $v s$. force for node 8 , linear material behavior. 
(a) Displacement Z vs. force in node 7.

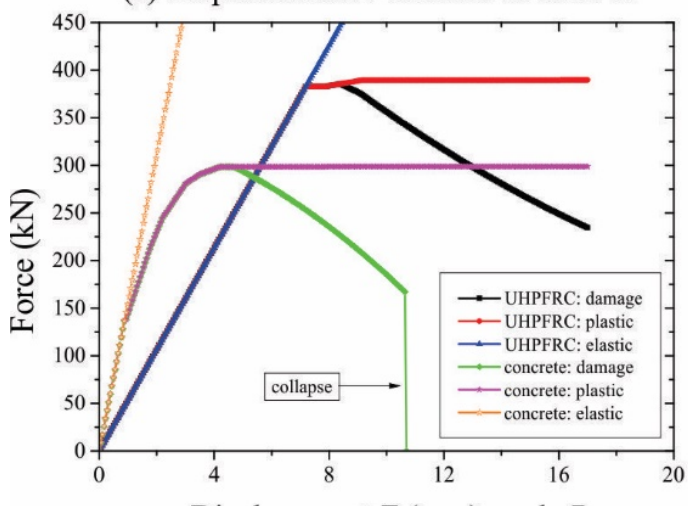

Displacement Z (mm): node 7

(c) damage evolution.

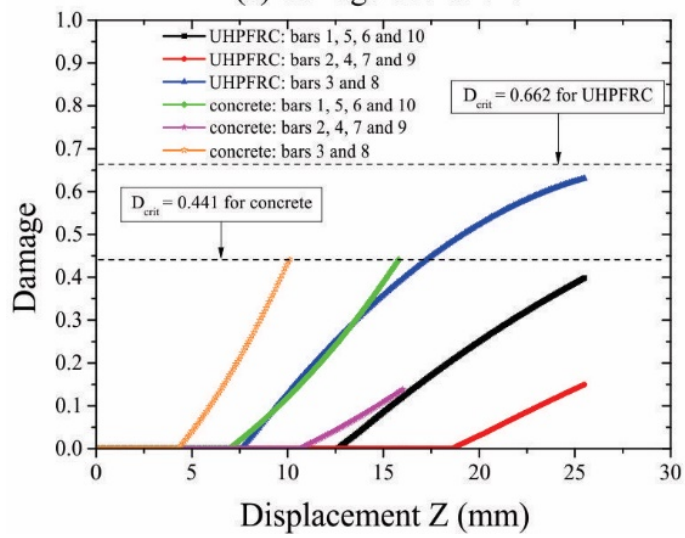

(b) displacement $\mathrm{Z}$ vs. force in node 8 .

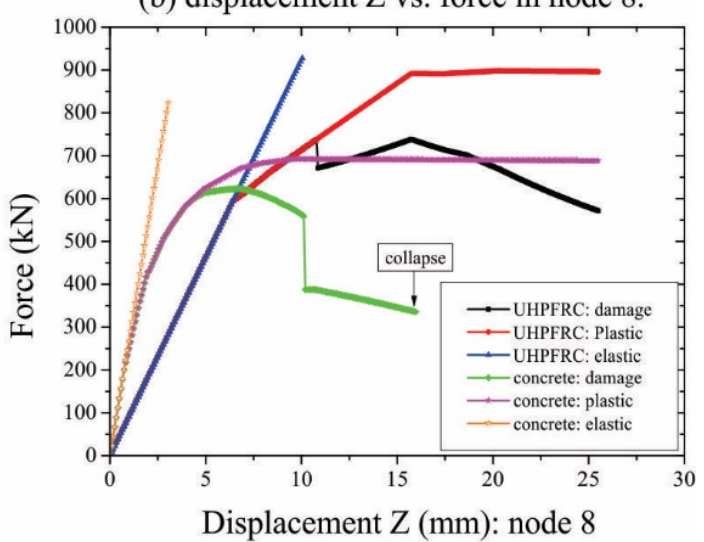

(d) total plastic strains.

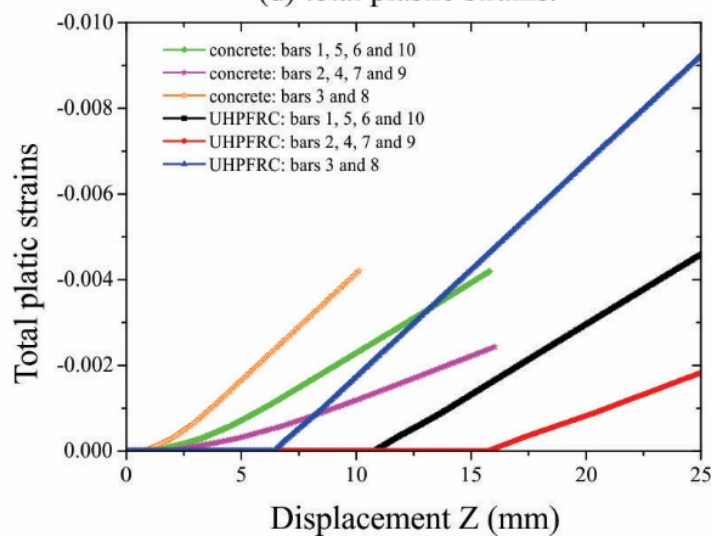

Figure 5. (a) Displacement $Z$ vs. force in node 7; (b) displacement $Z$ vs. force in node 8; (c) damage evolution in the bars and (d) total plastic strains in the bars.

In the context of plastic responses (Figure $5 b$ ), it is worth mentioning the loss of stiffness for displacements of 0.82 $\mathrm{mm}$ (conventional concrete) and $6.50 \mathrm{~mm}$ (UHPFRC), caused by plastic strains in elements 3 and 8 (Figure 5d). At displacements of $Z=9.13 \mathrm{~mm}$ (conventional concrete) and $Z=15.71 \mathrm{~mm}$ (UHPFRC), all elements (1 to 10) start yielding under constant stress in the plastic solution. Hence, the force vs. displacement curves become horizontal. For displacement levels higher than $9.13 \mathrm{~mm}$ (conventional concrete) and $15.71 \mathrm{~mm}$ (UHPFRC), the plastic response is singular (infinite displacement at constant force). In this case, softening behavior has not been accounted for in the pure plastic solution.

The proposed plastic damage model leads to consistent responses. For displacements of $0.82 \mathrm{~mm}$ (conventional concrete) and $6.50 \mathrm{~mm}$ (UHPFRC), one observes the plastic behavior of elements 3 and 8 (Figure 5d). For displacements of $4.36 \mathrm{~mm}$ (conventional concrete) and $7.65 \mathrm{~mm}$ (UHPFRC), elements 3 and 8 reach the initial damage threshold $\left(\varepsilon_{l n, d}^{p}\right)$. Thus, softening behavior appears.

For conventional concrete at displacements of $10.12 \mathrm{~mm}$, elements 3 and 8 reach critical damage (as seen in Figure 5c). Thus, these elements fail and a sudden drop in force is observed. To simulate the local failure of these elements, nearly zero Young's modulus is assumed for those bars that reach critical damage. The bars 1, 5, 6 and 10 reach the initial damage threshold at $6.99 \mathrm{~mm}$ of displacement, as seen in Figure $5 \mathrm{c}$. At a displacement of $15.79 \mathrm{~mm}$, these bars reach critical damage and fail. For displacement level equal to $10.69 \mathrm{~mm}$, bars 2, 4, 7 and 9 starts damaging (Figure $5 \mathrm{c}$ ). The complete collapse of the conventional concrete truss structure occurs for displacements of $Z=10,69 \mathrm{~mm}$ (node 7) and $Z=16.035 \mathrm{~mm}$ (node 8), as seen in Figure $5 \mathrm{a}$ and $5 \mathrm{~b}$.

For UHPFRC material and center node displacements in the range $10 \mathrm{~mm}$ to $15 \mathrm{~mm}$, the truss structure experiences load redistributions, which lead to higher force values of elements $1,5,6$, and 10 . The bars $2,4,7$ and 9 reach initial damage threshold for displacement level of $12.67 \mathrm{~mm}$. None of the bars composed of UHPFRC reaches critical damage, as seen in Figure 5c. Consequently, the progressive collapse of the 3D truss structure composed of UHPFRC does not 
occur for this displacement level. Then, in addition to higher strength, UHPFRC provides an improvement on the postfailure structural behavior. This material avoided the total structural collapse, which cannot be avoided in the case of conventional concrete.

\section{RELIABILITY ANALYSIS OF FAILURE PATHS}

\subsection{Basic formulation}

Uncertainties are intrinsic to the progressive collapse problem. The abnormal loads which may trigger a collapse event are characterized by small probability of occurrence, large and random intensities, and extreme consequences [2]-[5]. Material degradation behavior (ductility, damage) is usually associated to larger variance than conventional (linear elastic) material behavior [34], [35]. Hence, it is natural to use reliability theory to study the progressive failure of structures.

Probabilistic formulations in the literature address the hazards, the loading scenarios, and their probabilities [2]-[7]. However, most papers addressing the mechanics of load transfer as structural damage progresses are deterministic [12], [13], [19]-[25]. Formulations addressing the reliability of structures in progressive failure scenarios are rare [6]-[8], [14]-[18]. Hence, application of the FLHB model to the reliability analysis of truss structures in progressive collapse analysis of hyperstatic trusses is the main contribution of this paper.

One relevant point to make, when applying any numerical model in reliability analysis (instead of deterministic analysis), is that the reliability algorithm tests the structure a large number of times, for very different values of the random parameters. Hence, the algorithm needs to be both efficient and stable. Any numerical floating-point instabilities are more likely to be revealed in reliability than in conventional mean value analysis.

Let $\mathbf{R}=\left\{R_{1}, R_{2}, \ldots, R_{n}\right\}$ be a vector of random variables describing the uncertainties of the structural problem, such as material yield and ultimate stresses, geometry, load magnitudes, etc. Let $\mathbf{R}=\mathbf{r}$ denote a specific outcome of the random variable vector. A limit state equation $g(\mathbf{r})=0$ is written, dividing the domain of $\mathbf{R}$ into a survival domain $\left(\Omega_{s}\right.$ Os) and a failure domain $\left(\Omega_{f}\right)$, such that [35]:

$$
\left\{\begin{array}{l}
\Omega_{s}=\{r \mid g(\mathbf{r})>0\} \\
\Omega_{f}=\{r \mid g(\mathbf{r}) \leq 0\}
\end{array}\right.
$$

The fundamental problem in structural reliability is the assessment of the failure probability:

$$
P_{f}=P[g(\mathbf{r}) \leq 0]=\int_{\Omega_{f}} f_{\mathbf{R}}(\mathbf{r}) d \mathbf{r}
$$

where $P[]$ is the probability operator, $f_{\mathbf{R}}(\mathbf{r})$ is the joint probability density function of the $n$-dimensional vector $\mathbf{R}$. If all random variables are independent, $f_{\mathbf{R}}(\mathbf{r})$ can be determined by:

$$
f_{\mathbf{R}}(\mathbf{r})=\prod_{i=1}^{n} f_{R i}\left(r_{i}\right)
$$

where $f_{R i}\left(r_{i}\right)$ is the marginal probability density function (PDF) for random variable $R i$.

Due to difficulties in multi-dimensional integration, Equation 6 cannot be solved analytically, unless for very simple problems [35]. Two lines of approaches have been developed for solving Equation 6: simulation methods and transformation methods [35]. In this paper, the brute force Monte Carlo Simulation (MCS) and the First Order Reliability Method (FORM) are considered, as follows.

The Monte Carlo Simulation (MCS) method is intuitive and of very simple numerical implementation. Samples of the random variables $\mathbf{R}$ are generated, following the joint density function $f_{\mathbf{R}}(\mathbf{r})$ [34], [35]. For each sample $\mathbf{r}_{j}$, the 
limit state function $g\left(\mathbf{r}_{j}\right)$ is evaluated. An indicator function $I(\mathbf{r})$ is introduced to identify points in the failure domain, such that $I\left(\mathbf{r}_{j}\right)=1$ if $I(\mathbf{r}) \in \Omega_{f}$, and $I\left(\mathbf{r}_{j}\right)=0$ if $I(\mathbf{r}) \notin \Omega_{f}$. The failure probability is evaluated as:

$$
P_{f}=P[g(\mathbf{r}) \leq 0]=\int_{\Omega} I(\mathbf{r}) f_{\mathbf{R}}(\mathbf{r}) d \mathbf{r}=E[I(\mathbf{r})]
$$

In Equation 8, the term $E[I(\mathbf{r})]$ is the mean or expected value of the indicator function, which can be estimated from a finite number of samples $\left(n_{s}\right)$, as follows:

$$
P_{f}=E[I(\mathbf{r})] \approx \hat{P}_{f}=\frac{1}{n_{s}} \sum_{j=1}^{n_{s}} I\left[\mathbf{r}_{j}\right]=\frac{n_{f}}{n_{s}}
$$

where $\hat{P}_{f}$ is an estimate, and $n_{f}$ is the number of points sampled in the failure domain. It can be shown [34], [35] that Equation 9 is an unbiased estimate of the true failure probability; hence, $\hat{P}_{f} \rightarrow P_{f}$ when $n_{s} \rightarrow \infty$. In practical terms, for a limited computational budget, the number of samples is limited, and the estimate $\hat{P}_{f}$ is subject to a statistical sampling error. Roughly speaking, to keep this error limited to about $10 \%$, when evaluating a failure probability of the order $P_{f}=10^{-p}$, requires the number of samples to be around $n_{s} \approx 10^{p+2}$ [34], [35]. Hence, the required number of samples also depends strongly on the order of magnitude of the failure probability being evaluated.

A more efficient way of computing small failure probabilities is by way of transformation methods, like the First Order Reliability Method (FORM). The random variables are initially mapped from the original design space to the standard Gaussian space, using a transformation $\mathbf{V}=T[\mathbf{R}]$. Transformation $T[\mathbf{R}]$ involves eliminating eventual correlation between the random variables [34], [35]. In standard Gaussian space, variables $\mathbf{V}$ have zero mean and unitary standard deviation, and the joint density function $f_{\mathbf{V}}(\mathbf{v})$ becomes radially symmetric w.r.t. the origin. The most probable point of the failure domain, $\mathbf{v}^{*}$, is found by solving a minimization problem:

$$
\left\{\begin{array}{c}
\text { Find }: \mathbf{v}^{*} \\
\text { whichminimizes }: \mathbf{v}=\left(\mathbf{v}^{t} \mathbf{v}\right)^{1 / 2} \\
\text { subjectto }: g(\mathbf{v})=0
\end{array}\right.
$$

This minimization problem can be solved by the HLRF algorithm, proposed by [36], [37], or by other dedicated algorithms [34], [35]. The reliability index is the minimal distance between the limit state and the origin: $\beta=\mathbf{v}^{*}$. By approximating the limit state by a hyperplane, centered on $\mathbf{v}^{*}$, the first-order approximation to the failure probability is obtained as:

$P_{f} \approx \Phi(-\beta)$

where $\Phi($.$) is the standard normal cumulative distribution function (CDF).$

\subsection{Reliability of truss structures, conditional on loading}

In Section 5.1, the conventional formulation of structural reliability is presented. The formulation considers randomness in loads and/or strength variables.

In this paper, we focus on the strength of truss structures suffering progressive collapse. This is convenient since the numerical model is displacement-controlled. The prescribed displacement $\delta$ is the link between structural strength and the actual load effects. Truss strengths and conditional failure probabilities $(P[f \mid \delta])$ are evaluated for given $\delta$, and 
as a function of $\delta$. The actual displacement imposed on the structure is a function of actual load $(\delta(P))$, which is not addressed in the paper. This strategy is valid when only one independent load acts on the structure, or for a couple of dependent loads.

Hence, the failure probabilities in Section 5.1 are evaluated considering only strength random variables, leading to a conditional failure probability, $P[f \mid \delta]$. The (unconditional) probability of failure can be assessed through the total probability theorem, as follows:

$P_{f}=\int_{p} P[f \mid \delta(p)] f_{P}(p) d p$

where $f_{P}(p)$ is the density function of the random load. In this paper, we do not address the uncertainty in random loads; hence, we do not solve Equation 12, which is presented for completeness.

\subsection{Conditional failure events during progressive failure}

A failure path of a hyperstatic structure is the non-linear load-displacement response, from initial loading to complete loss of equilibrium. For a several-times hyperstatic structure, this includes a sequence of bar failures. When uncertainty in loading or in material response is considered, in principle, very different bar failure sequences can be observed. The number of failure sequences increases when independent loads act on the structure, or when independent material properties are assumed for different elements.

One significant difficulty in probabilistic analysis of progressive failure of several-times hyperstatic structures is handling the large number of possible conditional failure paths and branches, as illustrated in [6]-[8]. Analytical evaluation of the probabilities of each failure branch is quite involving, generally limited to a single or to fully dependent loads, or to the few more important failure paths and branches [38], [39]. One exception is the recent work of Feng et al. [18], which uses the probability density evolution method to evaluate failure path probabilities. The analytical addressing of failure paths allows one to consider "approximate" failure modes such as buckling of compressed members or simple rupture of tensile members.

In this paper, failure branch probabilities are handled by the Monte Carlo simulation and FORM algorithms. Individual and progressive bar failure events are handled by the non-linear material model. One acknowledged limitation of results presented herein in that either a single load is considered (Section 6.1), or fully dependent loads are considered (Section 6.2). Also, full dependence between material properties of different elements is considered, which is more realistic than assuming independence.

\section{STRUCTURAL RELIABILITY EXAMPLES}

\section{1 von Mises truss with analytical solution}

This section presents the reliability analysis of the von Mises truss. Results are presented in increasing order of complexity: linear elastic analysis is shown first, then geometrical nonlinearities are accounted for and, finally, geometrical and material nonlinearities are considered. Figure 6 illustrates the von Misses truss geometry and the constitutive models, typical of steel. Probabilities of failure are assessed through Monte Carlo Simulation (MCS) and the First Order Reliability Method (FORM). These solutions are compared and discussed in the following.

Table 5 describes the random variables and the assigned statistical properties. Nominal values for the parameters are as follows: the members are composed of tubular steel with circular cross-section of radius $r=5 \mathrm{~cm}$ and crosssection area $A_{0}=78.5 \mathrm{~cm}^{2}$. Young`s modulus is $E=20500 \mathrm{KN} / \mathrm{cm}^{2}$. Strength material parameters (for plastic analysis) are $\sigma_{y}=10 \mathrm{kN} / \mathrm{cm}^{2}$ and $\varepsilon_{y}=4.878 \times 10^{-4}$. The geometric parameters are: $x_{0}=200 \mathrm{~cm}$ and $y_{0}=10 \mathrm{~cm}$. The vector of random variables is assembled as: $\mathbf{R}=\left\{E, \sigma_{y}, r, A_{0}, x_{0}, y_{0}\right\}$. 


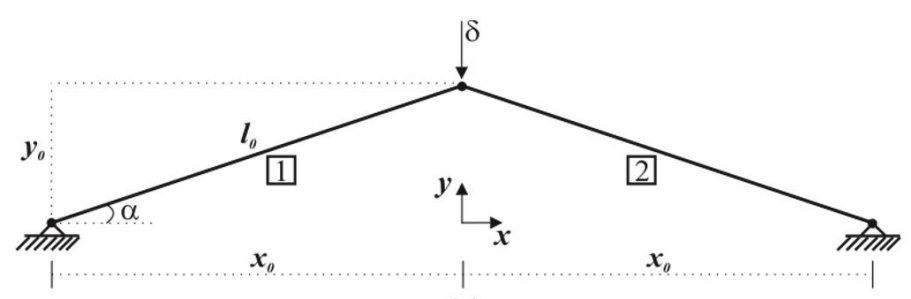

(a)

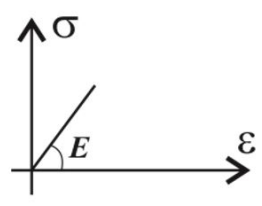

(b)

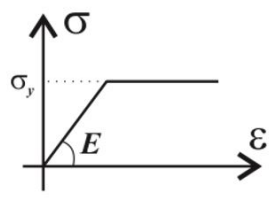

(c)

Figure 6. (a) geometric input data; (b) linear material response and (c) elastoplastic material response.

Table 5. Statistics for von Mises truss.

\begin{tabular}{|c|c|c|c|c|}
\hline Variable & mean & $\operatorname{cov}$ & distribution & ref. \\
\hline$E$ & $1.00 E$ & 0.03 & Lognormal & [35] \\
\hline$\sigma_{y}$ & $1.00 \sigma_{y}$ & 0.07 & Lognormal & [35] \\
\hline$A_{0}$ & $1.01 A_{0}$ & 0.04 & Normal & [40] \\
\hline$R$ & $1.00 r$ & 0.02 & Normal & [40] \\
\hline$x_{0}$ & $1.00 x_{0}$ & 0.02 & Normal & [40] \\
\hline$y_{0}$ & $1.00 y_{0}$ & 0.02 & Normal & [40] \\
\hline
\end{tabular}

The analytical solution for this problem, accounting for linear response, is obtained by enforcing the equilibrium at the initial configuration. In this case, the normal force is as follows:

$$
N_{\text {bar }}=-\frac{\delta E A_{0}}{\sqrt{x_{0}^{2}+y_{0}^{2}}} \sin \left[\arctan \left(\frac{y_{0}}{x_{0}}\right)\right]
$$

where $\delta$ is the prescribed displacement. Because material behavior is linear elastic and the bars are under compression, the limit state is written in terms of Euler buckling load as follows:

$$
g(\mathbf{r})=P_{c r}-N_{b a r}=\frac{\pi^{3} E r^{4}}{4\left(x_{0}^{2}+y_{0}^{2}\right)}-\frac{\delta E A_{0}}{\sqrt{x_{0}^{2}+y_{0}^{2}}} \sin \left[\arctan \left(\frac{y_{0}}{x_{0}}\right)\right]
$$

Figure 7a shows the values for conditional probabilities of failure ( $P[f \mid \delta] v s . \delta)$ assessed by FORM and MCS for the analytical limit state (Equation 14). The probability of failure values are largely dependent on the prescribed displacement value, as expected. The responses provided by FORM and MCS are in excellent agreement. It illustrates the efficiency of FORM, which handled a non-linear limit state (Equation 14) properly. It is worth mentioning that MCS and FORM are complementary in this solution. The probabilities of failure are quite low for small values of prescribed displacements. Thus, MCS may become prohibitive because of the computational cost. The amount of MCS samples is $n_{s}=10^{6}$; hence, MCS solutions are obtained for about $P[f \mid \delta]<10^{-5}$.

As illustrated in Figure 7a, the target reliability index ${ }^{1}$ of $\beta=4.2\left(P[f \mid \delta] \approx 10^{-5}\right)$ leads to the maximum displacement in linear elastic analysis equal to $4 \mathrm{~cm}$.

${ }^{1}$ JCSS [40], considering normal relative cost of safety measure and moderate consequences of failure. 
(a) comparison between FORM and MCS

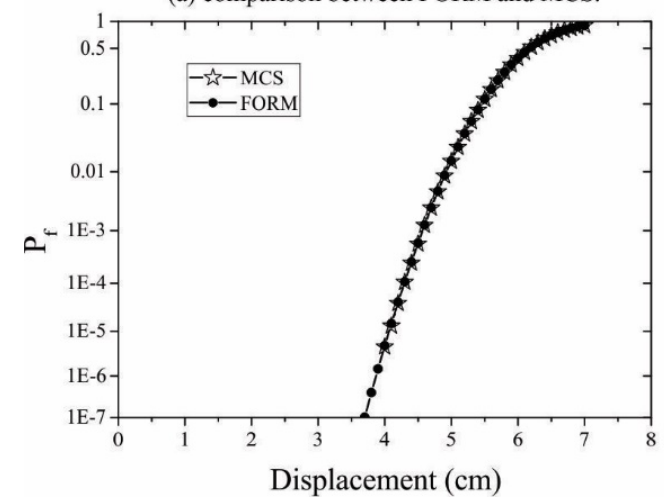

(b) numerical and analytical responses by MCS.

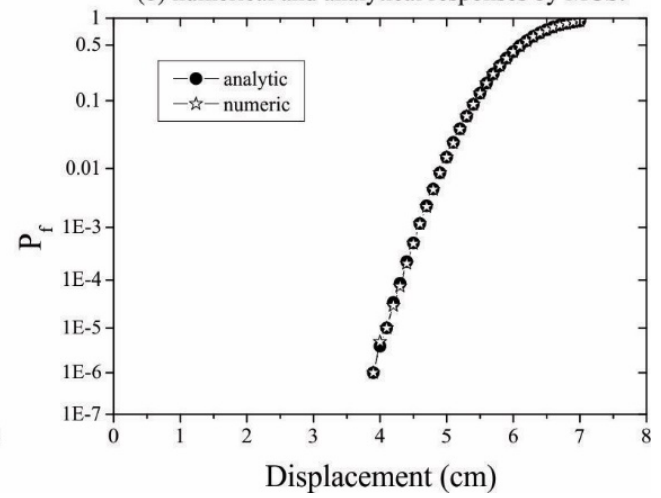

Figure 7. $P[f \mid \delta] v s$. displacement curve. Linear elastic solution for buckling: (a) comparison between FORM and MCS and (b) comparison of numerical and analytical responses by MCS.

To demonstrate accuracy of the FLHB non-linear formulation, the model was employed in the numerical analysis of the von Mises truss. However, geometric and material linear elastic behavior have been assumed. In this case, the limit state equation is written as follows:

$G(\mathbf{r})=P_{c r}-N_{\text {num }}=\frac{\pi^{3} E r^{4}}{4\left(x_{0}^{2}+y_{0}^{2}\right)}-N_{\text {num }}(\mathbf{r})$

where $N_{\text {num }}$ indicates the normal force value in the member from the numerical solution, which is a function of the random variables of the problem.

Figure $7 \mathrm{~b}$ compares the analytical and numerical solutions assessed by MCS. The numerical scheme provides results in excellent agreement with the analytical approach, which confirms the accuracy of the implementation. Because the Euler buckling load governs the failure mode (which is determined in the initial configuration), the normal force in numerical analysis is equal to the normal force from the analytical response.

The analysis becomes realistic when geometrical and material nonlinearities are accounted for. The material behavior is initially assumed as elastoplastic, as illustrated in Figure 6c. One hundred load steps are applied in the central node, with displacement control, for the accurate mechanical description.

The analytical elastic solution, for this case, is determined by equilibrium in the current configuration, which leads to:

$$
F_{a n}(\mathbf{r}, \delta)=2 E A_{0}\left\{1-\frac{\cos \left[\arctan \left(\frac{y_{0}}{x_{0}}\right)\right]}{\cos \left[\arctan \left(\frac{y_{0}-\delta}{x_{0}}\right)\right]}\right\} \sin \left[\arctan \left(\frac{y_{0}-\delta}{x_{0}}\right)\right]
$$

where $F_{a n}$ is the force conjugate to the $\delta$ applied in the central node.

Figure 8 illustrates the numerical solutions obtained by the FLHB model, accounting for geometrical and material nonlinearities. The numerical and analytical responses are in excellent agreement. It is worth remarking the complex mechanical behavior of this two-truss bar problem, in which tensile and compression normal force values have been observed. The limit forces are $77.3 \mathrm{kN}\left(F_{\text {lim,e }}\right)$ and $61.2 \mathrm{kN}\left(F_{\text {lim, }, p}\right)$, for the elastic and plastic materials, respectively. For such forces, the Hessian matrix determinant is nil. Notice that $F_{\text {lim }, p}$ is $26.3 \%$ smaller than the $F_{\text {lim }, e}$.

Also, a statistical analysis of $F_{\text {lim, },}$, and $F_{\text {lim, } p}$ is performed. From samples of random variables in Table 5, samples of $F_{\text {lim,e }}$, and $F_{\text {lim }, p}$ are obtained. The EasyFit software is employed to find the probability distribution and parameters for these variables. One hundred samples are computed. Table 6 presents the results. 
Table 6. Statistics for limit loads $F_{\text {lim,e }}$ and $F_{l i m, p}$.

\begin{tabular}{cccc}
\hline Variable & mean & Cov & distribution \\
\hline$F_{\text {lim,e }}$ & 78.1 & 0.11 & Lognormal \\
\hline$F_{l i m, p}$ & 59.3 & 0.09 & Lognormal \\
\hline
\end{tabular}

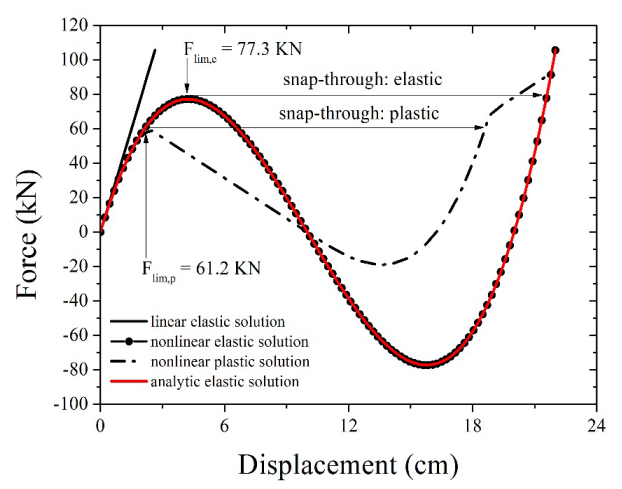

Figure 8. Load vs. displacement for geometrically nonlinear von Mises truss.

The limit state functions for non-linear analysis can be defined in terms of resistant forces and prescribed displacement $\delta$. For the (semi-)analytical solution, one has:

$g\left(\mathbf{r}, \delta, F_{\text {lim }, e}\right)=F_{\text {lim }, e}-F_{\text {an }}(\mathbf{r}, \delta)$

$g\left(\mathbf{r}, \delta, F_{\text {lim }, p}\right)=F_{\text {lim }, p}-F_{\text {an }}(\mathbf{r}, \delta)$

The corresponding limit state equation in the proposed numerical formulation is given as follows:

$g\left(\mathbf{r}, \delta, F_{\text {lim }, e}\right)=F_{\text {lim }, e}-F_{\text {num }}(\mathbf{r}, \delta)$

$g\left(\mathbf{r}, \delta, F_{\text {lim }, p}\right)=F_{\text {lim }, p}-F_{\text {num }}(\mathbf{r}, \delta)$

where $F_{n u m}$ is the force conjugate to the $\delta$ applied in the central node from the numerical solution, which is a function of the random variables of the problem.
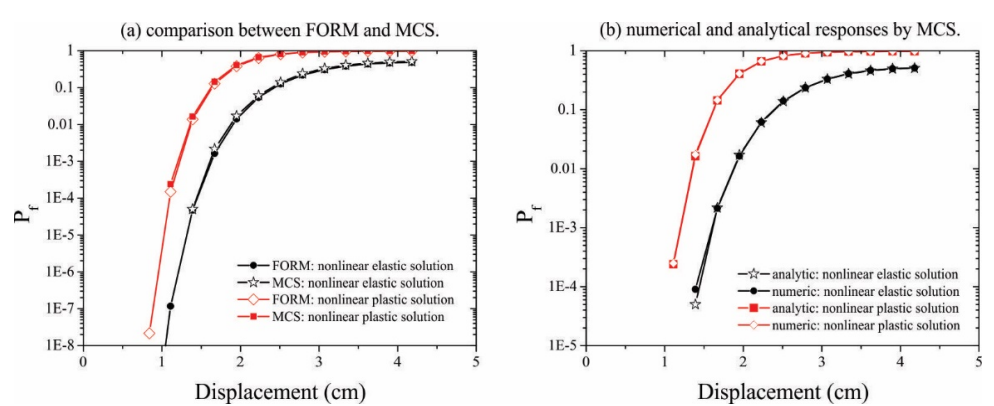

Figure 9. $P[f \mid \delta] v s$. displacement curve: (a) comparison between FORM and MCS (b) comparison between numerical and analytical responses by MCS. 
Figure 9a presents the $P[f \mid \delta]$ vs. displacement curves evaluated by FORM and MCS accounting for geometrical and material non-linearities. Notice the excellent agreement between the solutions even for the non-linear geometrical behavior. It is worth remarking that for the imposed displacement $\delta=4 \mathrm{~cm}$, the conditional failure probability is 0.5 . In the linear elastic solution, such a probability of failure value has been achieved for $\delta=6.1 \mathrm{~cm}$, as illustrated in Figure 7. It confirms that the geometrical nonlinear assumption has major importance in the failure analysis of the von Mises truss. For the same target reliability value of $P[f \mid \delta]=10^{-5}$, the maximum prescribed displacement in geometrically nonlinear elastic solution is $\delta=1.39 \mathrm{~cm}$, as illustrated in Figure 9a. As observed in Figure 9a, the assumption of non-linear material behavior increases the probability of failure, as expected. Hence, allowable displacements are much lower than in linear material and linear geometrical cases. For the target probability of failure $P[f \mid \delta]=10^{-5}$, the maximum prescribed displacement is $1.05 \mathrm{~cm}$. Figure $9 \mathrm{~b}$ compares the analytical and numerical responses computed by MCS, in which excellent agreement can be observed.

It is worth stressing that the evaluation of the previous statistics of limit loads $F_{\text {lim }, e}$ and $F_{\text {lim }, p}$ has been performed to facilitate the analysis for varying prescribed displacements $\delta$. This problem separation is not usually required because random limit loads (strengths) could be evaluated within the FORM or MCS solutions directly from $F_{\text {lim,e }}(\mathbf{r})$ and $F_{\text {lim, }, p}(\mathbf{r})$.

\subsection{Elastoplastic twelve-member 3D truss structure}

This example evaluates the reliability of the structure presented in Section 4. The 3D truss is composed of UHPFRC with nominal cross-sectional area $\mathrm{A}_{0}=1962.5 \mathrm{~mm}^{2}$. The mean and coefficient of variation (COV) of the cross-sectional areas are $\mathrm{E}[\mathrm{A}]=1.01 \mathrm{~A}_{0}$ and $\mathrm{COV}=0.04$. The damage model statistics are in Tables 3 and 4 . The vector of random variables is assembled as: $\mathbf{R}=\left\{\aleph, \sigma_{y}, A, D_{c r i t}, \varepsilon_{l n, d}^{p}, \alpha_{1}^{p}, \alpha_{2}^{p}\right\}$. Hence, limit state functions for each bar can be written in terms of the critical damage, as follows:

$g_{k}\left(\mathbf{r}, \delta, D_{\text {crit }}\right)=D_{\text {crit }}-D_{\text {num }}(\mathbf{r}, \delta), k=1,2, \ldots, 12$

where $D^{n u m}$ is the bar damage given by the numerical solution, which is a function of the vector of random variables and the prescribed displacements $\delta$.

Figure 10 shows the results for a deterministic (mean value) analysis, for which variables $\left\{\aleph, \sigma_{y}, A, D_{c r i t}, \varepsilon_{l n, d}^{p}, \alpha_{1}^{p}, \alpha_{2}^{p}\right\}$ assume their values mean. Figures 10a and $10 \mathrm{~b}$ show the displacement $\mathrm{Z} v s$. force curves of nodes 7 and 8, respectively, considering the proposed model. At point 1 occurs the first loss of stiffness of the truss structure, due to plastification of bars 3 and 8 . At point 2, bars 3 and 8 reach damage equal to 0.175 (see also Figure 10c), and a drop in force is observed (Figure 10b). This drop of force occurs because bars 3 and 8 enter the softening regime, under compression, as shown in Figure 2 for about the same damage level. Between points 2 and 3, the truss experiences load redistributions. Between points 3 and 4, all bars (except bars 11 and 12) are in the damage process; hence, softening behavior is observed. At point 4 bars 3 and 8 reach critical damage and fail, with a subsequent sudden drop in force (Figure 10b). Thus, these bars are removed to simulate local failure. At point 5 occurs the failure of bars 1, 5, 6 and 10, as they reach critical damage. This corresponds to the final collapse of this structure, which occurs under displacements $Z=30.80 \mathrm{~mm}$ (node 7) and $\mathrm{Z}=46.2 \mathrm{~mm}$ (node 8$)$. 
(a) displacement $\mathrm{Z}$ vs. force in node 7.

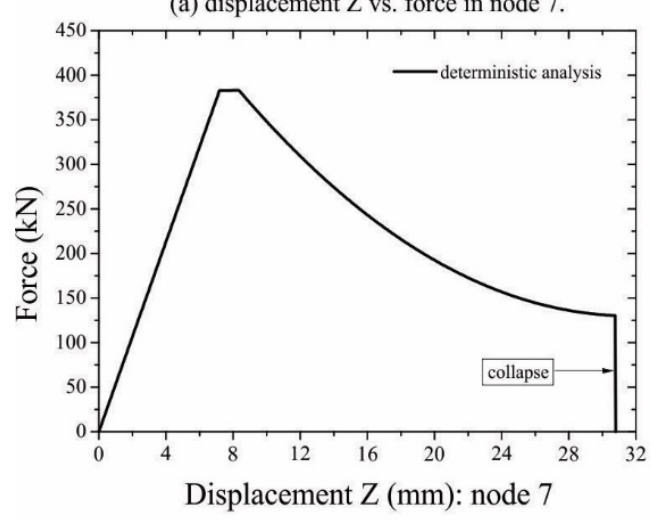

(c) damage evolution.

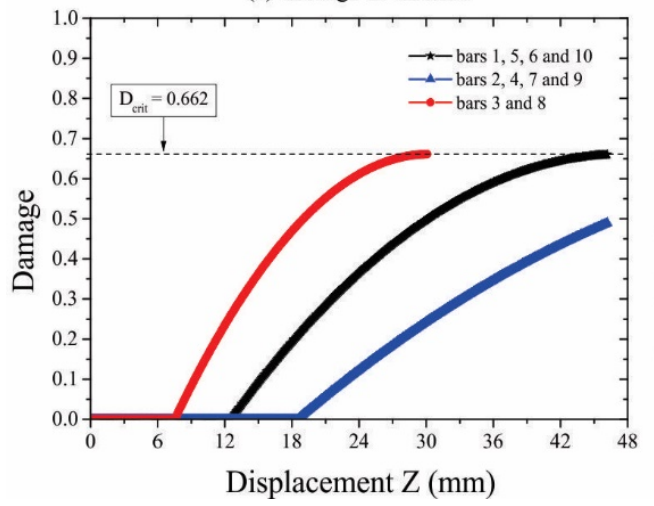

(b) displacement $\mathrm{Z}$ vs. force in node 8 .

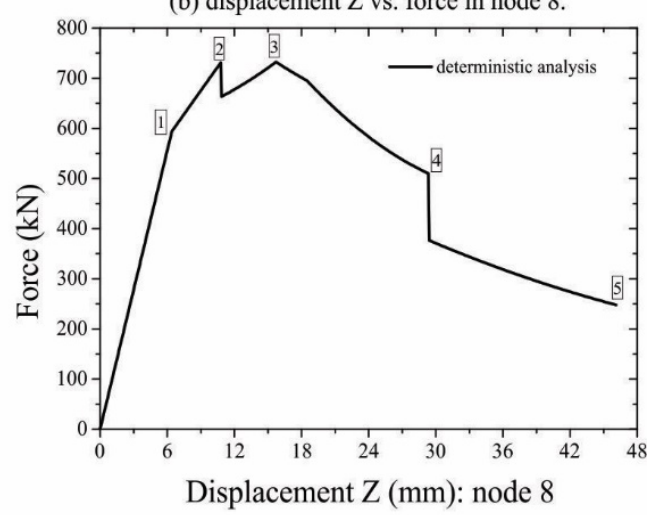

(d) total plastic strains.

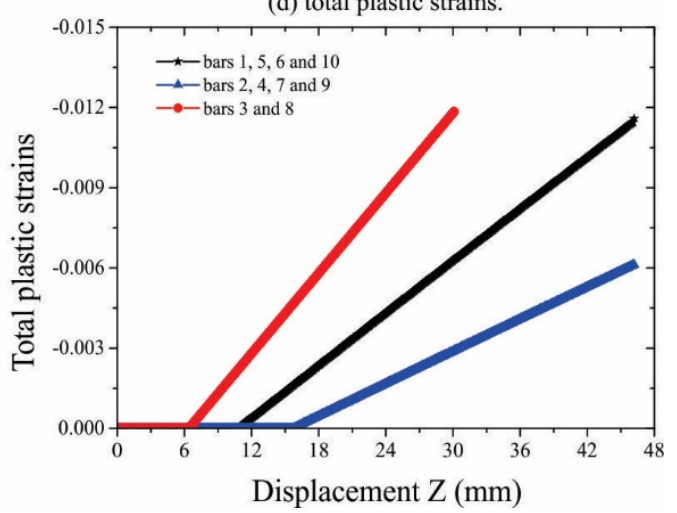

Figure 10. (a) Displacement $Z$ vs. force in node 7; (b) displacement $Z$ vs. force in node 8; (c) damage evolution and (d) total plastic strains in the bars: deterministic (mean value) analysis.

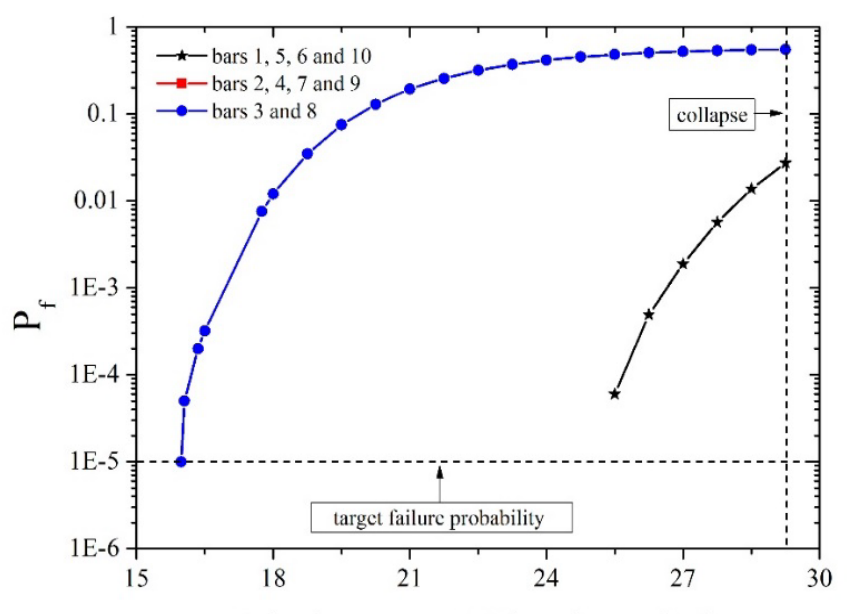

Displacement $Z(\mathrm{~mm})$ : node 8

Figure 11. $P[\mathrm{f} \mid \delta]$ vs. displacement curve by MCS.

Figure 11 shows the $P[f \mid \delta] v s$. displacement curve considering non-linear geometric and material behavior, which has been evaluated by MCS with $n_{s}=10^{5}$. The maximum allowable displacement is equal to $16.0 \mathrm{~mm}$ for the target failure probability of $P[f \mid \delta]=10^{-5}$. In the deterministic analysis, and for displacements up to $29 \mathrm{~mm}$, none of the members had reached critical damage (Figure 10b). However, considering the uncertainties of resistance variables, bars 3 and 8 achieve the target probability of failure for much smaller displacement values (around $16.0 \mathrm{~mm}$ ). For a 
prescribed displacement of $26.25 \mathrm{~mm}$, members 3 and 8 reach $P[f \mid \delta]=0.503$, while bars $1,5,6$ and 10 reach $P[f \mid \delta]=$ $4.9 \cdot 10^{-4}$. Remark that $P[f \mid \delta]=0$ for bars $2,4,7$ and 10 at this displacement level.

Figure 12 shows the displacement $Z$ vs. force curve in node 8 for one Monte Carlo sample leading to a full collapse of the truss. This curve was determined with $\mathbf{r}^{*}=\left\{\mathbf{N}, \sigma_{y}, A, D_{c r i t}, \varepsilon_{l n, d}^{p}, \alpha_{1}^{p}, \alpha_{2}^{p}\right\}=\left\{44692.42,127.77,2012.57,0.729,7.63 \times 10^{-5},-32863.1,422.54\right\}$. In Figure 12b it is possible to note that for $Z=18.5 \mathrm{~mm}$ (probabilistic analysis), bars 3 and 8 reach critical damage, leading to a sudden drop in force. Remark that in deterministic analysis those bars reach critical damage only for $Z=30.11 \mathrm{~mm}$. For this Monte Carlo sample, damage evolution presents a greater slope stronger than in the deterministic analysis, as illustrated in Figure 12c. This implicates that the displacement $Z$ vs. force curve presents more pronounced softening behavior (see Figure 12a). Finally, for $Z=29.25 \mathrm{~mm}$ the bars $1,5,6$ and 10 reach critical damage, which conducts to the full collapse of this structure. This displacement level leads to $P[f \mid \delta]=0.553$ (for bars 3 and 8 ) and $P[f \mid \delta]=0.0273$ (for bars 1, 5,6 and 10).

(a) displacement $Z$ vs. force in node 7 .

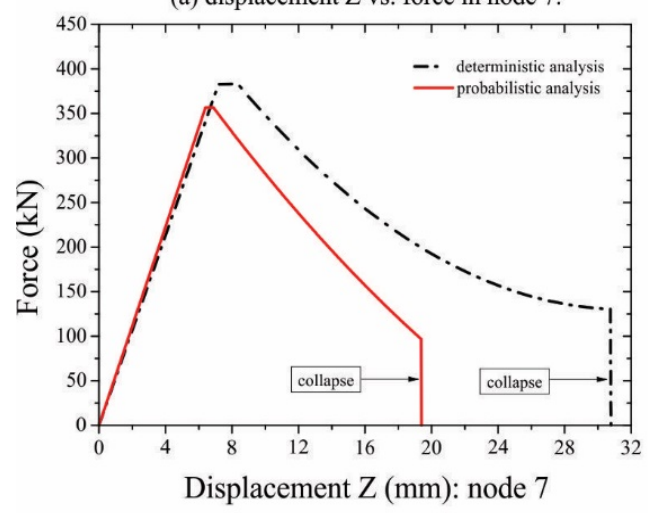

(c) damage evolution.

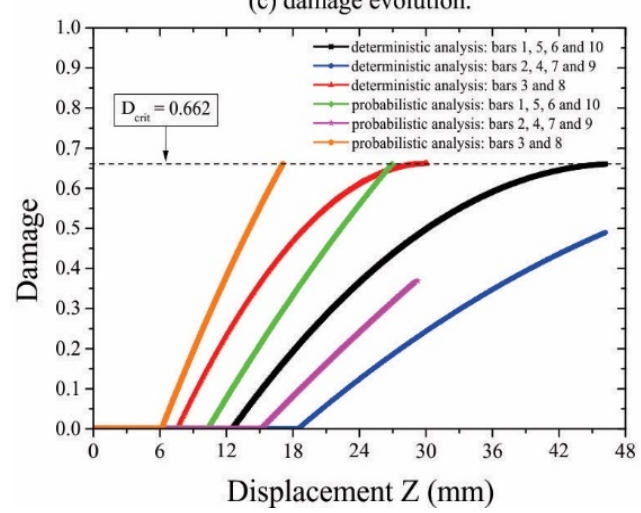

(b) displacement $\mathrm{Z}$ vs. force in node 8 .

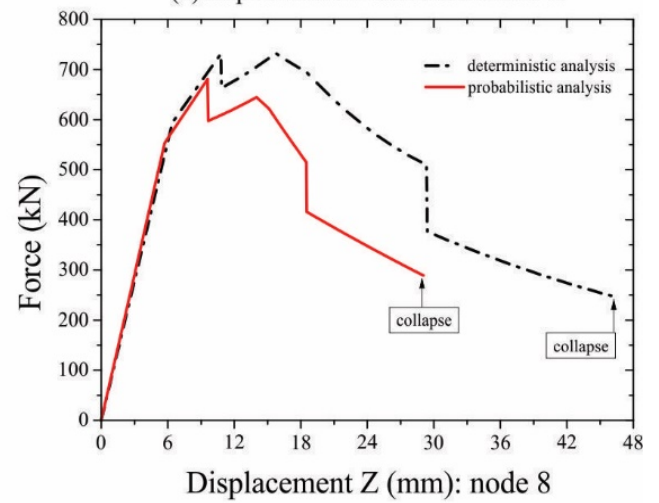

(d) total plastic strains.

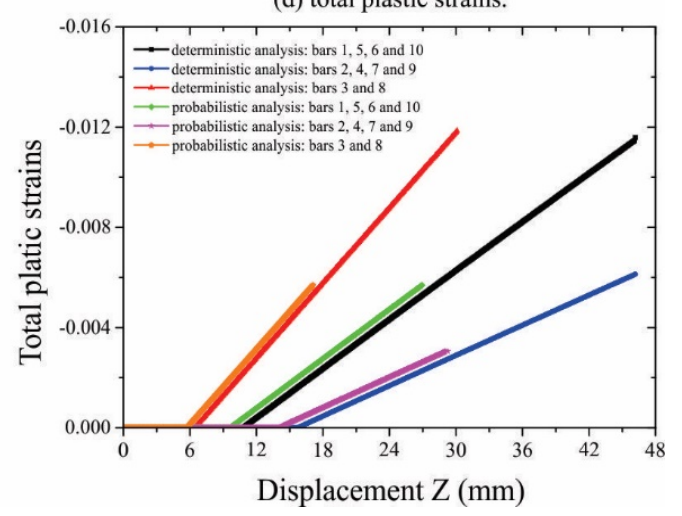

Figure 12. (a) Displacement $Z$ vs. force in node 7; (b) displacement $Z$ vs. force in node 8; (c) damage evolution and (d) total plastic strains in the bars: comparison between deterministic (mean value) and one sample of probabilistic analysis.

\section{CONCLUSIONS}

In this paper, the recently proposed [10] comprehensive ductile-damage FLHB model for truss structures has been employed to represent non-linear material responses of Ultra-High Performance Fiber Reinforced Concrete (UHPFRC). Based on a limited number of experimental curves, statistics of FLHB model parameters for UHPFRC have been obtained. These statistics were employed in the conditional reliability analysis of failure paths of truss structures, for imposed displacements.

It was demonstrated that the FLHB ductile-damage model accurately predicts the full stress-strain nonlinear response of UHPFRC, including the softening phase. Critical damage converges to the theoretical limit, avoiding numerical instabilities in element failures, leading to load redistributions until the complete structural collapse. An example problem has been presented comparing the failure paths of conventional concrete and UHPFRC trusses. Even 
being a fragile material, UHPFRC improves the structural ductility and leads to significant lower values of probability of failure in comparison with conventional concrete.

It was demonstrated, through two examples, that the FLHB model is both efficient and stable in the reliability analysis of complete truss structures experiencing progressive collapse. Load redistributions occur continuously after failure of individual members. The numerical model is non-linear but quite efficient, allowing even brute force Monte Carlo simulation for structures with moderate number of bars. Regardless of the significant non-linear geometrical and material behavior, it was shown that the First Order Reliability Method (FORM) provides accurate estimates of conditional failure probabilities, for prescribed displacements.

\section{ACKNOWLEDGEMENTS}

The authors acknowledge funding of this research project by Brazilian agencies CAPES (Brazilian Higher Education Council - Finance Code 001), CNPq (Brazilian National Council for Research, grant n. 306373/2016-5) and FAPESP (São Paulo State Research Foundation, grant n. 2017/01243-5). Valuable comments by the anonymous reviewers are also cheerfully acknowledged

\section{REFERENCES}

[1] J. M. Adam, F. Parisi, J. Sagaseta, and X. Lu, "Research and practice on progressive collapse and robustness of building structures in the 21st century," Eng. Struct., vol. 173, pp. 122-149, 2019.

[2] B. R. Ellingwood, "Mitigating risk from abnormal loads and progressive collapse," J. Perform. Constr. Facil., vol. 20, pp. 315-323, 2006.

[3] B. R. Ellingwood, "Strategies for mitigating risk to buildings from abnormal load events," Int. J. Risk Assess. Manag., vol. 7, pp. 828-845, 2007.

[4] B. R. Ellingwood, E. V. Leyendecker, and J. T. P. Yao, "Probability of failure from abnormal load," J. Struct. Eng., vol. 109, pp. 875-890, 1983.

[5] B. R. Ellingwood and D. O. Dusenberry, "Building design for abnormal loads and progressive collapse," Comput. Aided Civ. Infrastruct. Eng., vol. 20, pp. 195-205, 2005.

[6] T. R. C. Felipe, V. G. Haach, and A. T. Beck, "Systematic reliability-based approach to progressive collapse," ASCE ASME J. Risk Uncertain. Eng. Syst. A Civ. Eng., vol. 4, 04018039, 2018.

[7] R. K. Tessari, H. M. Kroetz, and A. T. Beck, "System reliability-based design optimization and risk-based optimization: a benchmark example considering progressive collapse," Eng. Optim., vol. 51, pp. 1000-1012, 2016, http://dx.doi.org/10.1080/0305215X.2018.1502760.

[8] A. T. Beck, "Optimal design of hyperstatic redundant structural systems: fundamentals," Eng. Struct., vol. 219, pp. 110542, 2020, http://dx.doi.org/10.1016/j.engstruct.2020.110542.

[9] H. B. Coda and R. R. Paccola, "A total-Lagrangian position-based FEM applied to physical and geometrical nonlinear dynamics of plane frames including semi-rigid connections and progressive collapse," Finite Elem. Anal. Des., vol. 91, pp. 1-15, 2014.

[10] T. R. C. Felipe, E. D. Leonel, V. G. Haach, and A. T. Beck, "A comprehensive ductile damage model for 3D truss structures," Inter J Non-Linear Mech, vol. 112, pp. 13-24, 2019.

[11] J. Lemaitre, A Course on Damage Mechanics. New York: Springer, 1992.

[12] S. Yan, X. Zhao, K. J. R. Rasmussen, and H. Zhang, "Identification of critical members for progressive collapse analysis of singlelayer latticed domes," Eng. Struct., vol. 188, pp. 111-120, 2019.

[13] L. M. Tian, J. P. Wei, and J. P. Hao, "Optimization of long-span single-layer spatial grid structures to resist progressive collapse," Eng. Struct., vol. 188, pp. 394-405, 2019.

[14] F. Miao and M. Ghosn, "Reliability-based dynamic analysis of progressive collapse of highway bridges," Procedia Eng., vol. 199, pp. 1170-1174, 2017.

[15] F. Miao and M. Ghosn, "Reliability-based progressive collapse analysis of highway bridges," Struct. Saf., vol. 63, pp. 33-46, 2016.

[16] Y. Ding, S. Song, and H. T. Zhu, "Probabilistic progressive collapse analysis of steel frame structures against blast loads," Eng. Struct., vol. 147, pp. 679-691, 2017.

[17] Y. Ding, S. Song, and H. T. Zhu, "Probabilistic progressive collapse analysis of steel-concrete composite floor systems," $J$. Construct. Steel Res., vol. 129, pp. 129-140, 2017.

[18] D.-C. Feng, S.-C. Xie, J. Xu, and K. Qian, "Robustness quantification of reinforced concrete structures subjected to progressive collapse via the probability density evolution method," Eng. Struct., vol. 202, 109877, 2020. 
[19] S. Szyniszewski and T. Krauthammer, "Energy flow in progressive collapse of steel framed buildings," Eng. Struct., vol. 42, pp. 142$153,2012$.

[20] B. Asgarian and F. H. Rezvani, "Progressive collapse analysis of concentrically braced frames through EPCA algorithm," J. Construct. Steel Res., vol. 70, pp. 127-136, 2012.

[21] M. Liu, "Progressive collapse design of seismic steel frames using structural optimization," J. Construct. Steel Res., vol. 67, pp. 322$332,2011$.

[22] H. S. Kim, J. Kim, and D. W. An, "Development of integrated system for progressive collapse analysis of building structures considering dynamic effects," Adv. Eng. Softw., vol. 40, pp. 1-8, 2009.

[23] J. W. Smith, "Structural robustness analysis and the fast fracture analogy," Struct. Eng. Int., vol. 16, pp. 118-132, 2006.

[24] S. Gerasimidis and J. Sideri, "A new partial-distributed damage method for progressive collapse analysis of steel frames," $J$. Construct. Steel Res., vol. 119, pp. 233-245, 2016.

[25] G. Kaewkulchai and E. Williamson, "Beam element formulation and solution procedure for dynamic progressive collapse analysis," Comput. Struc., vol. 82, pp. 639-651, 2004.

[26] J. Lemaitre and R. Desmorat, Engineering Damage Mechanics. New York: Springer, 2005.

[27] A. L. Gurson, "Plastic flow and fracture behavior of ductile materials incorporating void nucleation, growth, and interaction," Ph.D. dissertation, Brown Univ., Providence, RI, 1975.

[28] M. Greco, F. A. R. Gesualdo, W. S. Venturini, and H. B. Coda, "Nonlinear positional formulation for space truss analysis," Finite Elem. Anal. Des., vol. 42, pp. 1079-1086, 2006, http://dx.doi.org/10.1016/j.finel.2006.04.007.

[29] T. M. Siqueira and H. B. Coda, "Total Lagrangian FEM formulation for nonlinear dynamics of sliding connections in viscoelastic plane structures and mechanisms," Finite Elem. Anal. Des., vol. 129, pp. 63-77, 2017, http://dx.doi.org/10.1016/j.finel.2016.12.005.

[30] P. A. Krahl, R. Carrazedo, and M. K. El Debs, "Mechanical damage evolution in UHPFRC: Experimental and numerical investigation," Eng. Struct., vol. 170, pp. 63-77, 2018.

[31] S. Krenk, Non-linear Modeling Analysis of Solids and Structures. Cambdrige: Cambridge University Press; 2009.

[32] S. Krenk and O. Hededal, "A dual orthogonality procedure for nonlinear finite element equations original research article," Comput. Methods Appl. Mech. Eng., vol. 123, pp. 95-107, 1995.

[33] Y. B. Yang and L. J. Leu, "Constitutive laws and force recovery procedures in nonlinear analysis of truss," Comput. Methods Appl. Mech. Eng., vol. 92, pp. 121-131, 1991.

[34] A. . T. Beck, Reliability and Safety of Structures. Rio de Janeiro: Elsevier Campus, 2019.

[35] R. E. Melchers and A. T. Beck, Structural Reliability Analysis and Prediction. New Jersey: John Wiley \& Sons, 2018.

[36]. M. Hasofer and N. C. Lind, "Exact and invariant second moment code format," J. Eng. Mech., vol. 100, pp. 111-121, 1974.

[37]. R. Rackwitz and B. Fiessler, "Structural reliability under combined random load sequences," Comput. Struc., vol. 9, pp. 489-494, 1978.

[38] D. A. Onishchenko, "Analytical approach for estimating failure probability of multi-element structural systems with load-path history," Procedia Mater. Sci., vol. 3, pp. 1994-1999, 2014.

[39] P. Thoft-Christensen and Y. Murotsu, Application of Structural Systems Reliability Theory. Berlin: Springer, 1986.

[40]. JCSS Probabilistic Model Code, Joint Committee on Structural Safety 2001. http://www.jcss.byg.dtu.dk/Publications/Probabilistic_ Model_Code.aspx (accessed Jun 16, 2018).

Author contributions: TRCF: resources, computer programming, writing original draft; EDL, VGH: conceptualization, methodology, writing-review and editing; ATB: conceptualization, funding acquisition, methodology, supervision, writing original draft, writing-review and editing.

Editors: Bruno Breseghella, Guilherme Aris Parsekian. 